\title{
Why Am I Not Happy Anymore?
}

\section{Syeda Farah Batool}

Ziauddin University, Karachi, Pakistan.

Corresponding Author Email: farahbatool97@gmail.com

Received 03/05/2018; Accepted 25/09/2018; Published 10/10/2018

\begin{abstract}
Background: A person needs to be happy to be a functional unit of the society and to add a positive and productive contribution on his behalf to the welfare of humanity. There is a very close interaction between sex and joy, and no one can escape from the fact that sexual interaction is mostly a pleasurable experience. The objective of this study was to determine the prevalence of compulsive sexual behavior among youth and to find a relation between happiness and sexual activity. Methodology: This cross-sectional survey was conducted in Karachi-Pakistan. 300 subjects of both genders participated in this study while Sadaf Stress Scale (SSS) was used to evaluate the stress level of the individuals and a section of the questionnaire contained questions about the routine activities, sexual needs and its severity. Results: Results have shown that the symptoms of hypersexuality are prevalent among the youth of ages between 18 to 25 years. While $27 \%$ of unmarried subjects have experienced sex and $49 \%$ reported masturbation or phone sex is found to be the source of happiness. Conclusion: Unfortunately, hypersexuality is not yet considered as a psychological disorder/issue in many regions of the world which gives rise to brutal and feeble act like "Sexual abuse". It's high time to look into this matter before it's too late.
\end{abstract}

\section{Keywords}

Happiness, Sexual activities, Hypersexuality, Pain, Compulsive Behavior

\section{Introduction}

Is SEX a key core of happiness?

Undoubtedly, strong relationships play a vital role in building a strong and stable personality of an individual. A person cannot serve the society well if his mental and/or physical health is not satisfactory. A person needs to be happy to be a functional unit of the society and to add a positive and productive contribution on his behalf to the welfare of humanity (P. Alex Linley, 2009).

The most important thing to be a strong contender of wellbeing, he/she must feel good about him/herself. Euphoria, contentment, delight, joy, gratitude and pride all refer to one feeling that is happiness (P. Alex Linley, 2009).
Who doesn't want to be happy?

From the beginning, humans are trying to get that one feeling "Happiness", and they mostly do anything to achieve that sensation (Diener \& Diener, 1996). Here the question arises that what exactly this feeling is? A psychology researcher Sonja Lyubomirsky wrote in her book "The How of Happiness" that; "The feeling which makes you think that you are a positive well-being and makes you realize that your life has some meaning and it's worthwhile is known as "Happiness" (Lyubomirsky, 2009). There are so many phenomena that count for people's well-being and happiness like; 


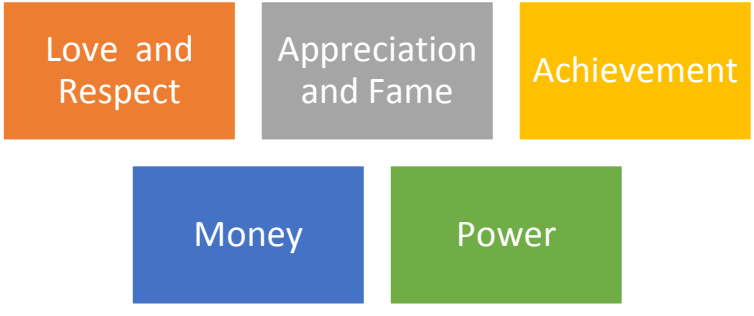

Figure 1: Sources of happiness, (Assisi, 2018)

Researchers have found that humans need to be completely indulged in an activity to feel happy (Bradt, 2015). An activity itself is not a happy activity or a sad activity, it is something in your brain that perceive a specific situation in a certain manner. This perception may vary from person to person. For instance, a situation which makes you feel happy can make others sad or feel nothing. The relation between the person, situations, and circumstances collectively leaves an impact on human's perception (Bradt, 2015). Some people might feel happy in what they are doing and are satisfied with what they have. But the existence of those people cannot be neglected who feel happy to see others in pain (Colino, 2017).

Based on psycho-social behaviors, people can be classified into these groups; i.e. grateful and satisfied and others are unsatisfied and distressed (Baker, 2011). Those who are grateful for what they have and satisfied with what they are doing can live a peaceful life. But unsatisfied and distressed members of the society may lead to the destruction of his own and others' lives (Baker, 2011).

Jealousy, anger, envy, greed is some of the core reasons behind being distressed and unsatisfied (Chhikara, 2013). This clan of stressed people will need something extraordinary or sometimes evil deeds to achieve or to be in a satisfying state (Kathrym, 2013). Sometimes in severe cases, people usually feel happy while

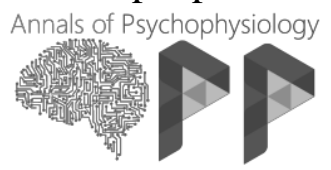

witnessing someone in distress or to imply their power on someone (Baker, 2011). People use different ways to gain a satisfactory sense. For example:

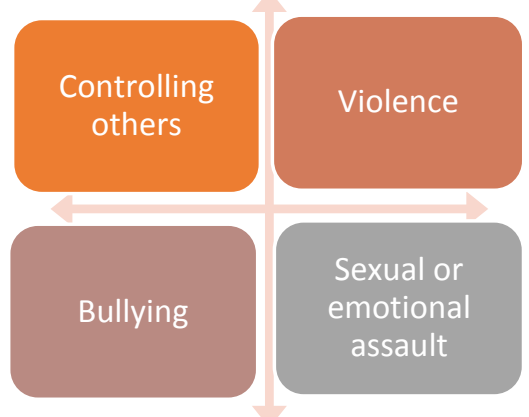

Figure 2: Use of power (Chhikara, 2013)

But the focused criteria of this study is to dig deep into the relationship between "Sexual activities and Happiness".

There is a very close interaction between sex and joy, and no one can escape from the fact that sexual interaction is mostly a pleasurable experience (Kashdan, 2014). Many people have different sexual personalities. People might express their love and affection through sexual contact or they might elucidate their anger and hatred by means of sex (Kathrym, 2013).

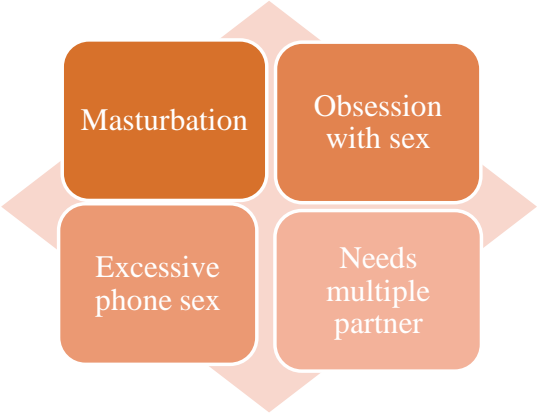

Figure 3: Symptoms of hypersexuality (Batool, 2017)

Normally when people have an intense sexual interaction with their partners, they usually feel relaxed and calm (Batool, 2017). If a person expresses his love via intimate interactions; this could be a satisfactory experience for both the partners. But if someone wants to impose 
his detestation, hate or power this might lead to worst experience for either or both the partners or only to the victim (Chhikara, 2013).

In Pakistan, the number of incidents of sexual abuse greatly increases during the past few years. (Ferozi, 2018). Especially with the children and young adults. According to a non-government organization 'SAHIL', approximately 11 cases of "Rape and Murder" are reported in Pakistan every day (Ferozi, 2018). The rate is highest in Punjab i.e. 1089 and in Sindh i.e. 490 cases in 2017 (Ferozi, 2018). This issue demands a great deal of attention. The increasing rate of 'Sexual Abuse' in the world, especially in Pakistan is an alarming situation not only for the authorities but for all of us. There can be enormous reasons behind this, but an uncontrollable urge to have sex, or in other words 'Hypersexuality or Compulsive Sexual behavior' might be the core reason (Freimuth et al., 2008). Hypersexuality is the increased frequency of sexual desire or intimacy.

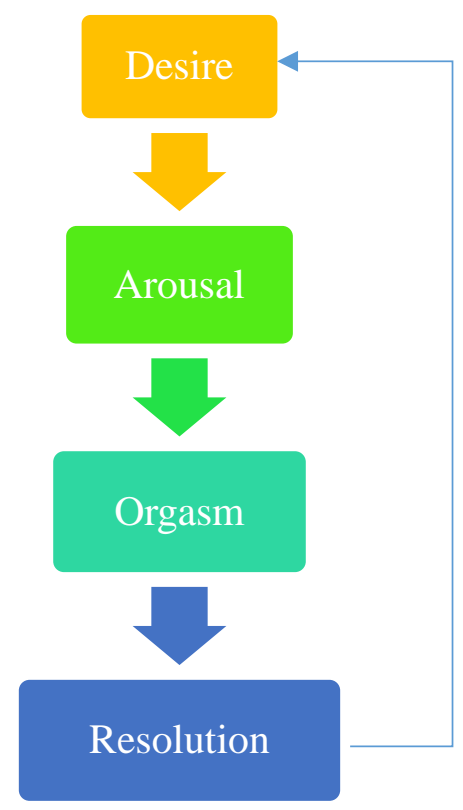

Figure 4: Cycle of intimacy (Keith \& Montgomery, 2008)

But in some cases, the gap between resolution and desire is very less, or mostly Annals of Psychophysiology

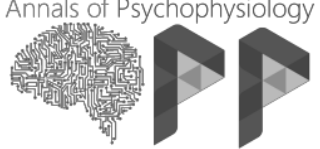

neglectable, which will give rise to an urge of sex (Keith \& Montgomery, 2008). Sometimes this feeling is uncontrollable that a person can even abuse others to get distressed. Generally, it happens that an individual is not happy with one partner, especially men as their emotional, physical and sexual needs are much different than a woman (Assari, 2018).

Sexual abuse is itself a very pitiful act rather attempt such feeble sin to make others suffer. It is proven through many researches that sometimes the cost of your happiness is someone else's pain (Kathrym, 2013). Some people feel happy when they impose their power onto others. To cause one to suffer from pain could be a great source of contentment to another (Brenner, 2016).

A publicly discussed incident of "Rape and Murder" of a 6-year-old girl child, on 4th January 2018 (Tribune, 2018), was an inspiration behind this study.

\section{Methodology}

A cross-sectional survey was conducted in a population of about 300 participants with their consent. Some of the data was also collected from the male customers in prostitution bars with their proper consent. But for privacy issues, the source and subjects cannot be disclosed.

During this survey, all the participants were asked to fill a questionnaire. Subjects were then assessed and analyzed based on the answers given. These subjects belonged to different educational and ethnic groups. Married and unmarried, both groups are included in this study. An average age group of the subjects in this study is between 18-25 years, (with few exceptions of 26 - 28 years).

To make analysis easier subjects were divided into Group: 1 Male and married, Group: 2 Male and unmarried. Group: 3 
Female and married Group: 4 Female and unmarried. Sadaf Stress Scale (SSS) was used to check the emotional, traumatic and psychological stress whereas Microsoft Excel was used to calculate and shaping the results into graphical forms. All the subjects with severe PTSD and other psychological disorders were excluded. To avoid biasness and subject manipulation most of the questions in the survey were kept open-ended.

\section{Results}

Results that were obtained from analyzing the data are alarming. When subjects were asked to answer the questions following responses were obtained.

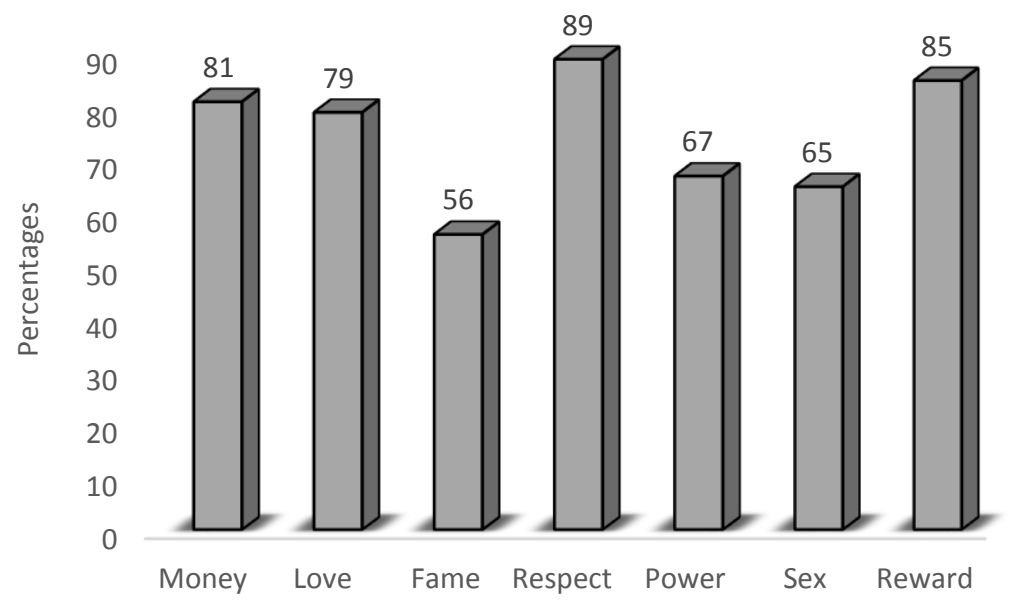

Figure 5: Things that give feelings of happiness

Figure 5 shows the percentage of subjects who mentioned things that make them happy and $65 \%$ of them have reported Sex as a process which can bring happiness.

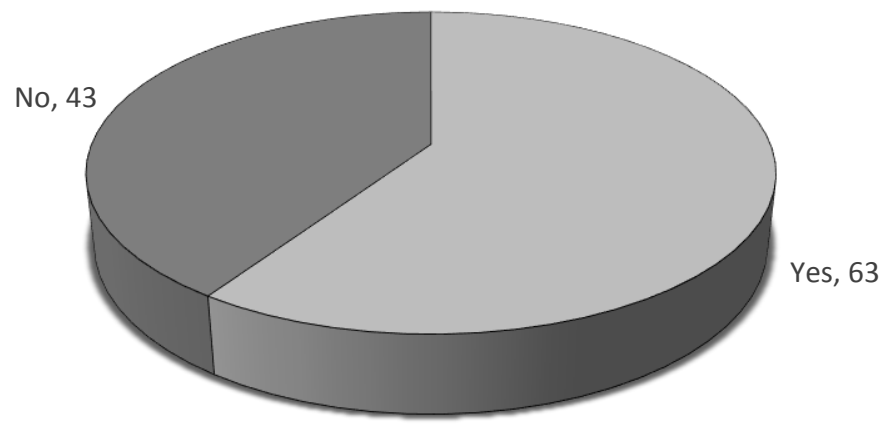

Figure 6: Prevalence of Stress and pain in study subjects

Figure 6 shows the percentage of the subjects that are suffering from deep pain and stress and most of them had a traumatic background of different severities. 


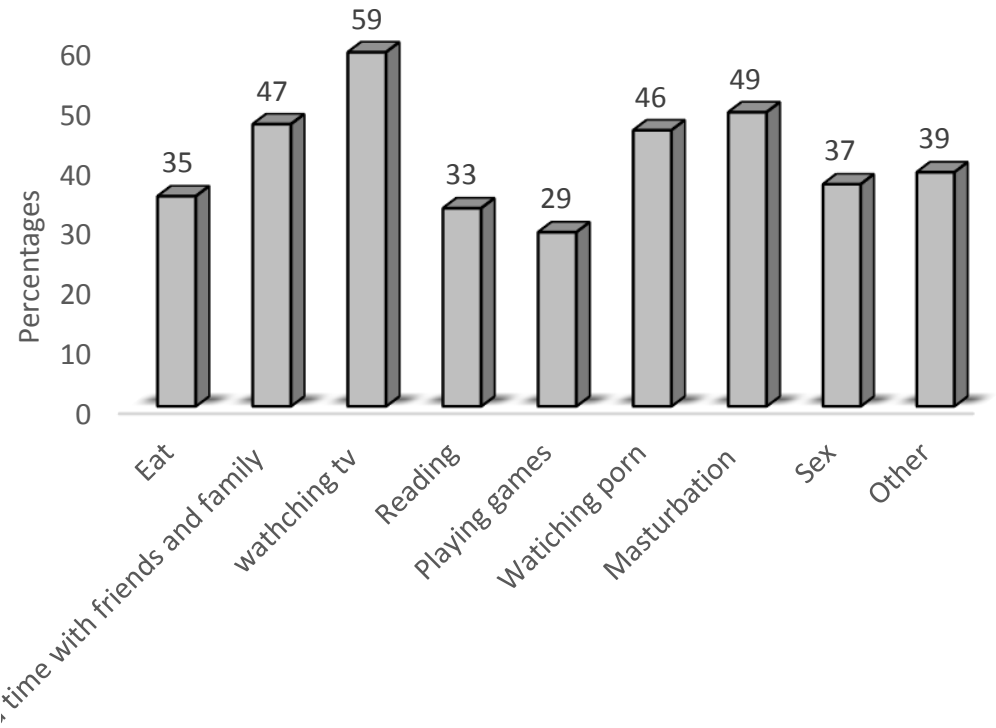

Figure 7: Coping strategies with Stress

Figure 7 shows the percentage of the methods or practice subjects used by the subjects of the study to cope with the stress and many participants have reported that smoking and masturbation as a practice that helps them to de-stress themselves.

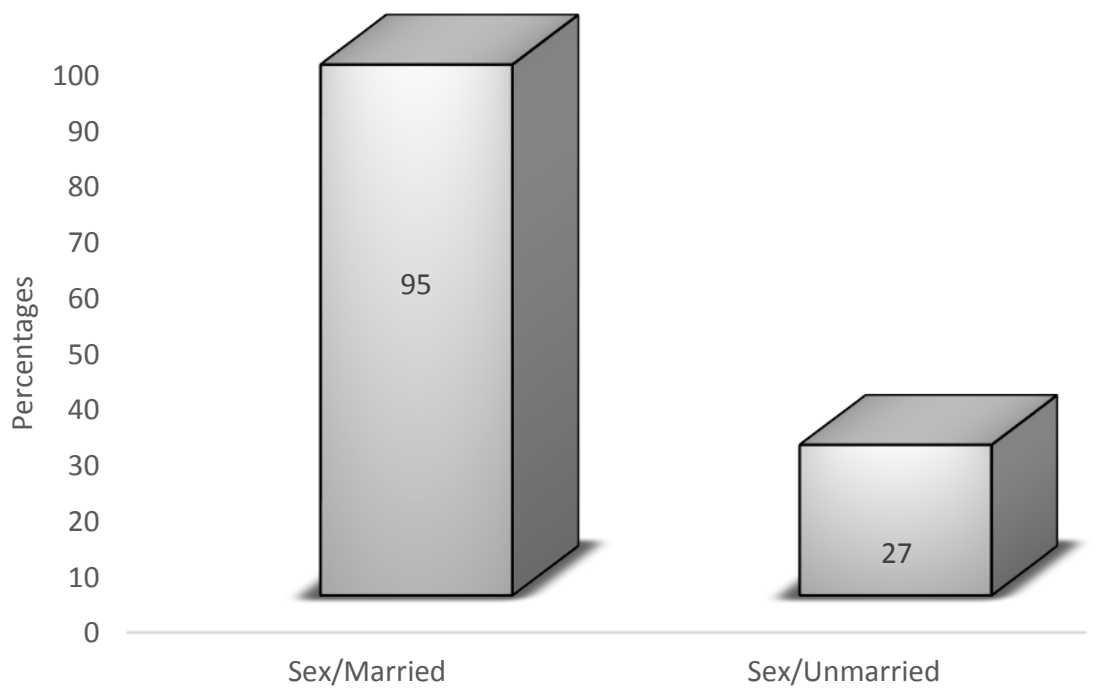

Figure 8: Participants who have experienced sex both in married and Un-married groups.

When the subjects of both the groups (married and unmarried) were asked about their sexual life, an unexpected result was attained. Figure 8 shows the percentage of the participants who have experienced sexual intercourse both in married and unmarried groups. 


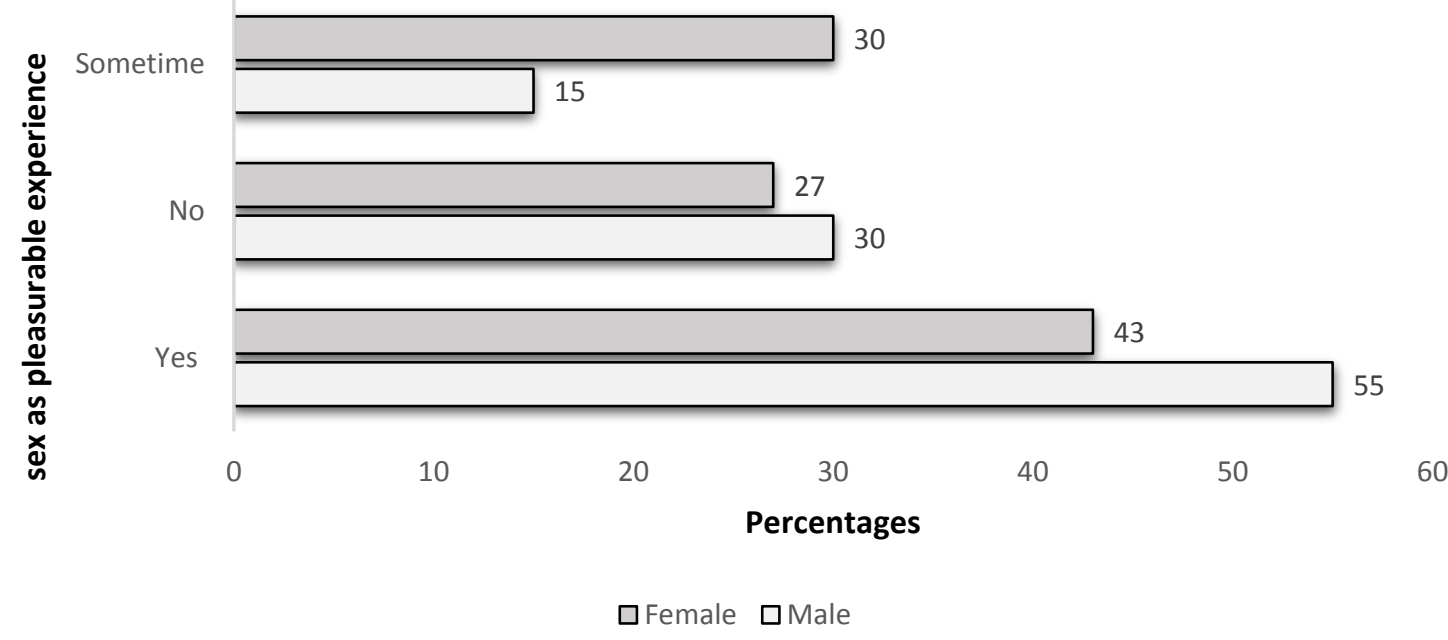

Figure 9: Subjects who perceive sex as a pleasurable experience.

Figure 9 shows the percentage of the subjects that perceive sex as a pleasurable experience or not. There are a few participants who have reported that sometimes this is a pleasurable experience and sometimes it's not.

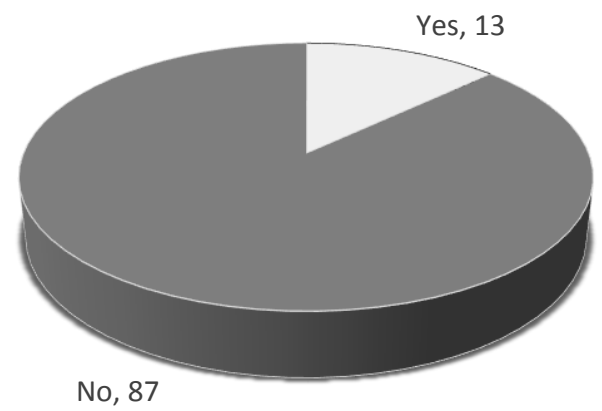

Figure 10: Individuals who had abused someone

The worst part of an individual's personality has come to life when he abuses someone. Figure 10 shows the percentage of the participants who have abused someone. 


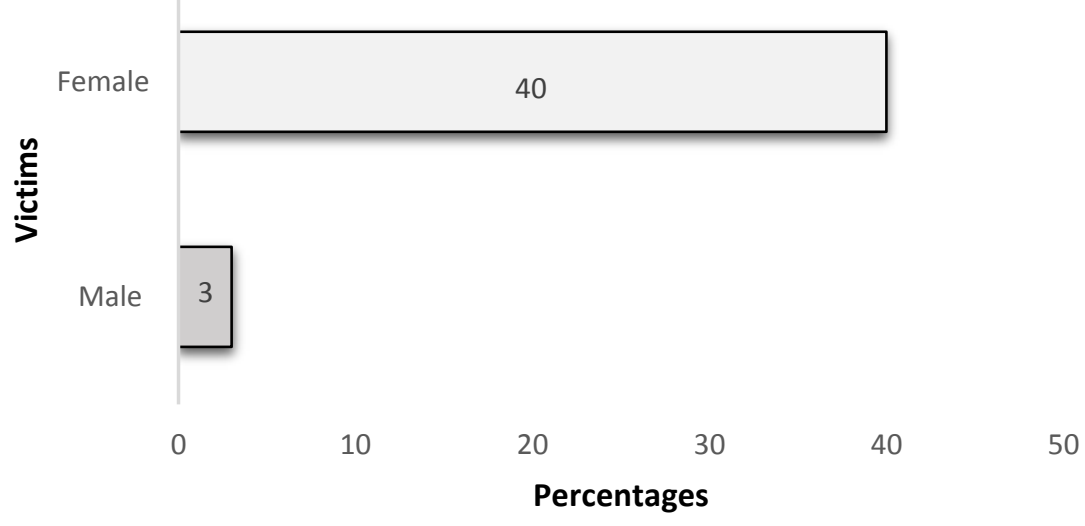

Figure 11: Victims of sexual abuse and assault in both male and female

It is hard to confess about a bitter truth of abuse, but facing the reality makes it easier to survive. Figure 11 shows the percentage of the victims of sexual abuse and assault in both male and female.

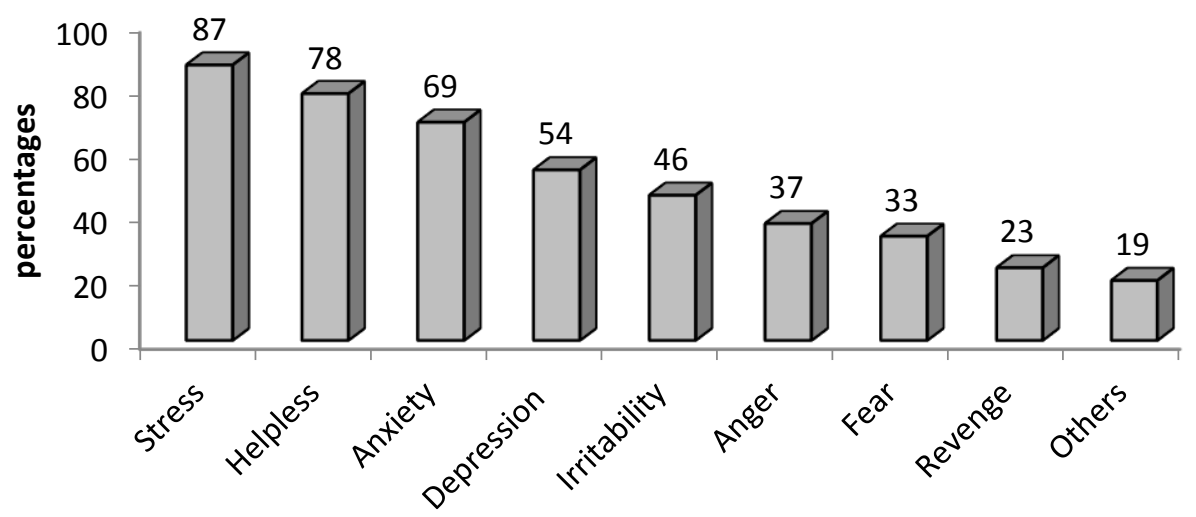

Figure 12: Signs and symptoms experienced by the victims of abuse.

A person may suffer from a cascade of the symptoms of post-traumatic stress disorder after a traumatic event. Figure 12 shows the percentage of the most reported signs and symptoms of the victims of sexual abuse. 


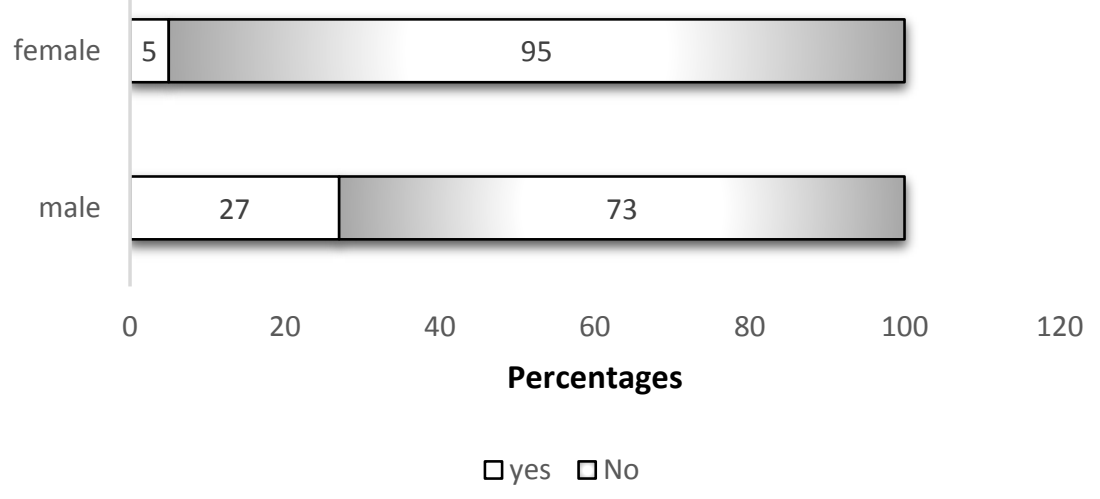

Figure 13: Abusing someone give happiness

When subjects were asked that abusing someone make you happy? The results were shocking $27 \%$ of males have reported that harassing or abusing someone could be a reason for the pleasure of an individual. Figure 13 shows the exact results.

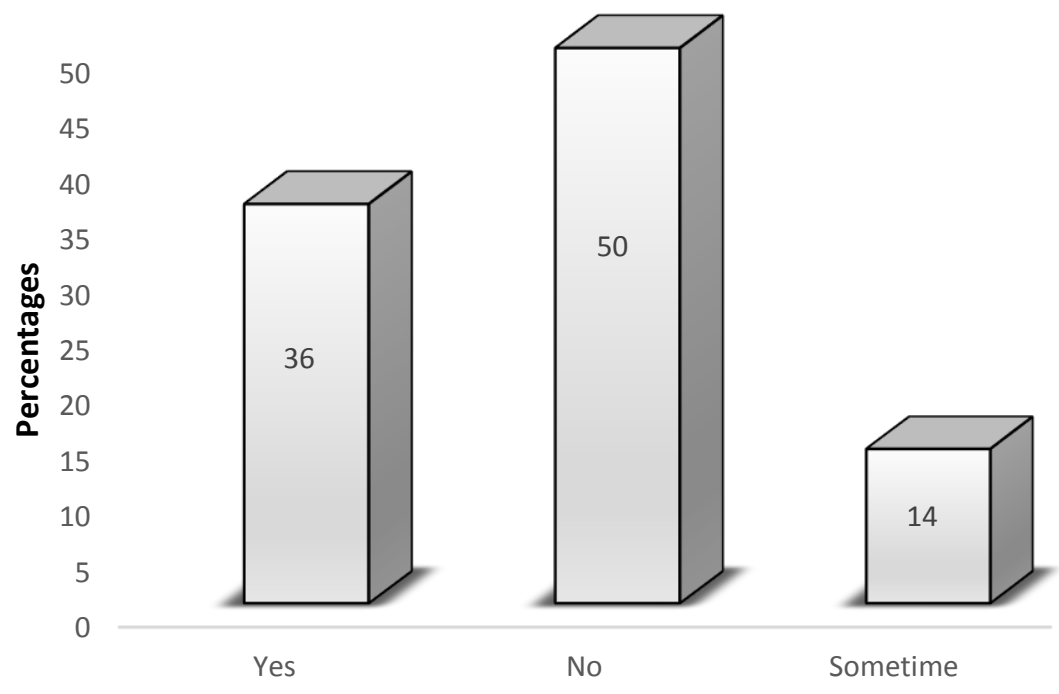

Figure 14: Perceive pain as a pleasure

Pain of any sort could be the worst experience for an individual, but sometimes pain could be a source of satiety especially if it is of others. Figure 14 shows the percentage of the subjects who perceives Pain as a pleasure.

There are some distinct mentions other than the statistical analysis. When the subjects were asked that 'how many times in a week one must have sex?' The answers vary from 3 times to 14 times* a week. When the highest time mentioned subjects were inquired further $37 \%$ * of them have reported that the frequency, as well as the intensity of the sex, is highly important to extract pleasure.

*Note: The results only implicate males of both groups Married and Un-married 


\section{Discussion}

Sex could be a pleasurable experience and has many health benefits without a doubt, as it is a natural need of living beings to make sexual contacts with their mates, people feel happy after any sexual activity or sexual intercourse (Stuart, 2010). The needs of male and female are totally different in terms of intensity and frequency (Kinsey, 1998.). That might be the reason why more men opted for different intimate means as compared to women (Kinsey, 1998.). In figure $5,65 \%$ of the participants have mentioned that sex is a source of happiness for them and many perceive Sex as a pleasurable practice. Unfortunately, the excessive urge to have sex or hypersexuality is yet not considered as a psychological disorder because there is no upper limit of having sex. There are no such measures through which this condition could be diagnosed. Sex can undoubtedly be a pleasurable experience if both partner's concern is taken (Assari, 2018). But this could be miserable one if one is forced to intimate. Figure 6 reveals the ratio of stress among the subjects. The high value of stress means less satiety and if a person doesn't feel satisfied he will seek for more (Baker, 2011). In a city like Karachi, which is the busiest and one of the most stressful city in the world people don't need to look up for stress because it stays at their doorstep. For youngsters, the biggest terror is 'Exams', for teen its 'Love' or 'Relationships' and for married couples its 'Family occupation' (Harvey, 2004).

On contrary to this there are so many reasons to stay happy and grateful for example being able to perform daily work, got a chance to meet your friend after a long time. So, we all are surrounded with a bunch of stresses and plenty of reasons to smile, but the choice is ours (Baker, 2011). Sometimes reason of contentment has shifted to a negative side, and individual start to seek joy only in activities like drinking, smoking, sex or abuse (Kathrym, 2013).

Usually, a more depressed person experiences bad sex or an unwanted or bad sex may lead to depression because it stimulates stress cascade in our brain (Assari, 2018). According to this study 43\% subjects were in pain or moderate or severe stress and have a traumatic background (Figure 6), and when they were asked that what they do to relive their stress approximately $49 \%$ subjects have reported by watching porn/masturbation or by having sex (Figure 7). Results have revealed that about $27 \%$ of unmarried subjects have experienced sex and about $13 \%$ have tried or did abuse someone (Figure 8 \& Figure 10 respectively). Although in many countries having sexual interactions before marriage or live-in relationships are common and acceptable but in Pakistan, it's still considered as a bad thing as the majority of the population are Muslims, and in such a country this number is alarming! More shocking thing is that a considerable number of the participants of this study wanted to abuse someone and $40 \%$ of the subjects were abused most of them were female (Figure 11).

As after a bad sex you feel stressed (Figure 12 ), it shows that $87 \%$ have felt stressed after being abused, $74 \%$ felt helpless after the incident and approximately $60 \%$ have reported anxiety irritability and anger as their symptoms. This is a huge number of individuals and it is with no doubt that stress can lead to massive personality issues.

When subjects were inquired that whether they perceive pain as a pleasure or not $36 \%$ were yes and $14 \%$ said sometimes (Figure 14). Aldous Huxley wrote in his book "Brave New World" in 1932, that; "Endless pleasure may lead to dystopian societies". 
"So, pain must be there to feel the goods around us". But if someone is addicted to pain and causes others to suffer is a psychological condition (Keith \& Montgomery, 2008). It is proven that psychological health matters a lot to build stable and strong relationships (Bradt, 2015)

\section{Conclusion}

Psychology has become a blooming science since past few decades. There are so many psychological issues which need to be dealt with appropriately. Unfortunately, Pakistan is lacking in this issue as there are so many social and cultural norms that in captivate the people. People usually don't speak up for such things which are making the situation even worse. Especially a topic like SEX or RAPE is such a 'no' 'no' word in most families. That might be the reason why 'rape' cases are increasing massively. Talking to someone is the best therapy to relieve stress. We need to build tolerance for others and should try to listen to them. The symptoms of compulsive sexual behavior can be controlled if we try to consider as an issue which needs to be resolved.

\section{Conflict of Interest}

None.

\section{Acknowledgment}

Hearty gratitude to all the participants and my teachers especially Dr. Sadaf Ahmed and Mr. Faizan Mirza for supporting me throughout the journey.

\section{Funding}

None.

\section{References}

- Assari, S. (2018). Consensual sex is key to happiness and good health, science says. The conversation. Retrieved from: http://theconversation.com/consensual- sex-is-key-to-happiness-and-good-

health-science-says-91384

- Assisi, C. (2018, April Sunday). Money, power, fame, love. live miint. Retrieved from:

https://www.livemint.com/Sundayapp/jj d7mZEchQoLqSikcXjlbM/Moneypower-fame-love.html

- Baker, M. (2011). It's good to be grateful: gratitude interventions at work. East Carolina, United states: MARTHA BAKER. Retrieved from https://core.ac.uk/download/pdf/719738 50.pdf

- Batool, S. F., \& Ahmed, S. (2017). Prevalence of compulsive sexual behavior/hyper sexuality disorder and its psychological manifestations in youth. Annls Psychophy, 4, 59-66.

- Bradt, G. (2015). The secret of happiness. forbes. Reterived from: https://www.forbes.com/sites/georgebra $\mathrm{dt} / 2015 / 05 / 27 /$ the-secret-of-happinessrevealed-by-harvardstudy/\#1c058ca46786

- Brenner A. (2016). 9 Classic Traits of Manipulative People. Psychology Today. Retrieved from https://www.psychologytoday.com/ca/b log/in-flux/201610/9-classic-traitsmanipulative-people

- Brody, S. (2010). The relative health benefits of different sexual activities. $\mathrm{J}$ Sex Med, 7(4pt1), 1336-1361.

- Chhikara, P., Jakhar, J., Malik, A., Singla, K., \& Dhattarwal, S. K. (2013). Review research paper domestic violence: The dark truth of our society. J Indian Acad Forensic Med, 35, 71-75.

- Colino, S. (2017). The Roots of Schadenfreude: Why We Take Pleasure in Other People's Pain. U.S News. Retrieved from https://health.usnews.com/wellness/min d/articles/2017-03-01/the-roots-ofschadenfreude-why-we-take-pleasurein-other-peoples-pain 
- Dawson, G. N., \& Warren, D. E. (2012). Evaluating and treating sexual addiction. Am Fam Physician. 86(1), 74.

- Diener, E., \& Diener, C. (1996). Most people are happy. Psychol Sci, 7(3), 181185.

- Desk, N. (2018). Zainab rape-murder: Was suspect Imran Ali known to his neighbours? THE EXPRESS TRIBUNE. Reterived from: https://tribune.com.pk/story/1618251/1zainab-rape-murder-suspect-imran-aliknown-neighbours/

- Ferozi, M. (2018). 11 children are abused in Pakistan every day: report. Daily Times. Retrieved from: https://dailytimes.com.pk/183445/11children-abused-pakistan-every-dayreport/.

- Freimuth, M., Waddell, M., Stannard, J., Kelley, S., Kipper, A., Richardson, A., \& Szuromi, I. (2008). Expanding the scope of dual diagnosis and co-addictions: Behavioral addictions. J Groups Addict Recover. 3(3), 137-160.

- Harvey John, W. A. (2004). The Handbook of Sexuality in Close Relationships. (J. H. Susan Sprecher, Ed.) London: Lawrence Erlbaum Associates, Publishers.

- Kashdan, T. B., Adams, L. M., Farmer, A. S., Ferssizidis, P., McKnight, P. E., \& Nezlek, J. B. (2014). Sexual healing: Daily diary investigation of the benefits of intimate and pleasurable sexual activity in socially anxious adults. Arch Sex Behav, 43(7), 1417-1429.

- Kathrym, P. M. (2013). Why Do People Abuse? MentalHelp.net. Retrieved from https://www.mentalhelp.net/articles/wh y-do-people-abuse/

- Keith A. Montgomery, M. (2008). Sexual Desire Disorders. Psychiatry (Edgmont). 2008; 5(6): 50-55.

- Kinsey, A. C., Pomeroy, W. B., Martin, C. E., \& Gebhard, P. H. (1998). Sexual Behavior in the Human Male.
Bloomington, USA: Indiana University Press; 335-362.

- Lyubomirsky, S. (2009). The How of Happiness: A New Approach to Getting the Life You Want. Penguin Books

- P. Alex Linley, J. (2009). Measuring happiness: The higher order factor structure of subjective and psychological well-being measures. Science direct, 878-884.

doi:https://doi.org/10.1016/j.paid.2009. 07.010

- Waite, A. M. (2013). Sexual activity and psychological health as mediators of the relationship between physical health and marital quality. J Gerontol B Psychol Sci Soc Sci, 482-492. 